\title{
Role of Travel Behaviour Characteristics in Selecting Wellness Services at Tourism Destination
}

\author{
K. Subathra, S. Senthil Kumar, T. Ramachandran
}

\section{ABSTRACT}

The main plan of this manuscript was to explore the peculiarities between the three kinds of visitors: Spiritual retreat, Beauty spa and Health resort visitors with reverence to choosing tourism destination and their socio demographic, travel behaviour characteristics. Data was collected from as a division of a investigate on tourists' activities on a part of vacationers visiting and also residing at least one night in tourist service offered places in India. Respondents are international tourists to India specifically to the wellness tourism destinations such as Kerala, Karnataka, Tamilnadu and Pondicherry who are drawn from the study population. They may have used services from the three types of services and must be an international visitor to India. As Chennai, Bangalore, Kottakal, \& Auroville were the few places of wellness tourism from each of the destinations mentioned above which is a representative of the requisite population the samples were drawn from above mentioned places. Few chi square tests for independence were performed to check if there exists any significant difference among the three types of wellbeing visitors with reverence to their demographic and voyage behaviour distinctiveness. Noteworthy dissimilarities among three types were initiated from the facet of sample travel behaviour distinctiveness, socio demographic, visiting other tourism destinations.

Index Terms: Wellness, Travel behaviour, India.

\section{INTRODUCTION}

Twenty first century India has turn into a main destination for health and wellness tourism. Wellbeing is tailed by health groups with the prime aim of prevention, whereas 'cure' tourists want to be healed, recover or recuperate from illness. The most common resources for this have traditionally been mineral waters and climate, but increasingly, health includes not only physical but also mental and psychological problems Mueller, H., \& Kaufmann, E. L. (2001). This is when the definitions of health and wellness start to become more complex and convergent. Wellness tourism is an essential economic action and represents to be the fastest growing segment. Therefore it's naturally

Revised Manuscript Received on July 05, 2019.

K. Subathra, Research scholar and Assistant Professor, Faculty of Management,SRMUniversity, Chennai,603203,India.

Dr. S.Senthil Kumar, Assistant Professor, Faculty of Management, SRM University, Chennai.,

Dr. T.Ramachandran, Professor, Faculty of Management, SRM

University, Chennai.,ramachandran.t@ktr.srmuniv.ac.in. comprised among the top three industries in the country. However India has developed many things since the fifties with respect to wellness tourism. But India has still the way behind the developed or even the developing countries. India earns one seventh of China, one forth of Indonesia, and less than half of Philippines from tourism. Many foreign countries have already started wellness service centers and the export of wellness products and services to international market is increasing in a faster way day by day. But surprisingly foreign tourists are look forward and keen to pursue the origin of the practice to avail treatments and body purification processes. The fundamental principles emerging from a holistic outlook, the particular and unique techniques of treatments and the health promoting and non reactive herbal drugs used are the main elements which differentiate wellness services from the other prevailing medical system. From the past two decades, the necessity for a holistic approach in the treatment of diseases had been an active topic for discussion among the scholars of modern services completely rejuvenating the body, mind, spirit and which ultimately promotes the basic health.

\section{LITERATURE REVIEW}

Mueller, H., \& Kaufmann, E. L. (2001) understood that the twenty first century Kingdom of India become a serious sector for health and wellness touristry. However more and more, health includes not solely physical however additionally mental and psychological issues. This could be once the definitions of health and wellness begin to become a lot of advanced and merging. Kickbusch, I., \& Payne, L. (2003) mentioned the longer term of health promotion; they have a tendency to neglect a serious influential trend in well-groomed societies: the increasing privatization of health promotion. Hence defined in different areas of social life, society has seen what monumental power the market and customers will exert and they need urged to explore the general public health and wellness revolutions may meet to supply higher health. Smith, M., \& Kelly, C. (2006) argued theories thrive on the explanations for this exponential growth, several of that name the un oriented of western, capitalist societies, the breakdown of ancient spiritual, and therefore the division of communities. Therefore they revealed wellness is state of one may simply be healthy however not essentially happy. Smith, M., \& Puczkó, L. (2008) highlighted the 'wellness' is wide engaged in European touristry and revealed wellness is pursued exclusively by 'healthy' individuals, the prime aim 
being interruption. Therefore 'Normal cure' guests aim to heal their health problem. Laing, J., \& Weiler, B. (2008) declared that in recent years there has been notable rise in interest in health and wellness touristry, as well as spa and medical touristry, that area division seen as sub sectors of the broader wellness touristry development. Further explained there were division forms of reasons for this, as well as relief of stress moreover as beauty edges and a lot of speedy access to smart quality surgical interventions. So they revealed Asia has benefited from this demand thanks to associate array of social cultural and economic factors. Hence the complementary and different medications area unit presently acceptable at everyday was in a very heap of cases used before the progress of standard medicine. As a result of we have a tendency to sense that the holistic move toward to wellness through holidays will greatest to be experiential and focusing in wellness services. Erfurt-Cooper, P., \& Cooper, M (2009) studied wellness (alternative medicine): wellness is mostly accustomed mean a healthy balance of mind, body, spirit that lead to overall feeling of upbeat. These approaches discuss wellness from another medication perspective wherever wellness suggests that being far more than simply illness free. Zhou, B., \& Fang, W. (2012) have found that there have been deficiencies on the idea of regional wellness touristry, management mode of regional wellness touristry, wellness touristry culture, and development levels, etc. Wellness (medicine) here, successfulness refers typically to the state of being healthy. Kelly, C. (2010) analysis has shown that retreat operators were a comparatively distinctive cluster of wellness touristry suppliers to that degree as they're poorly organized put together (compared, as an example, to the spa sector); the overwhelming majority will be classified as 'lifestyle entrepreneurs' in terms of their business motivations and aspirations; several own, manage and teach at their centers, and their views on and engagement with coaching, regulation and therefore the touristry sector itself area unit much place-specific. Voigt, C., Brown, G., \& Howat, G. (2011) explored and compared the benefits sought-after by three differing types of upbeat tourists: beauty spa, mode resort, and non secular retreat guests. Whereas all participants within the study wanted transformation of the self, every specifiable cluster of tourists placed completely different stress on physical, psychological or non secular transformations. Moreover, every cluster differed considerably in terms of demographic and travel behaviour characteristics. Lehto, X. Y., Brown, S., Chen, Y., \& Morrison, A. M. (2006) have researched the socio-demographic and psychological feature characteristics of yoga tourists and provided empirical evidences that a human involvement level with yoga, physical health likewise as mental well-being completely contribute to the propensity to travel for yoga. Heung, V., \& Kucukusta, D. (2013) have examined the potential for wellness touristry development in terms of resources and promotion from the purpose of read of wellness touristry consultants. They need surveyed professionals operating in touristry, health and education results unconcealed that environmental assets, as well as contemporary air, clean water and natural options, were thought-about the foremost vital attributes for the event of wellness touristry. Chen, K. H., Liu, H. H., \& Chang, F. H. (2013) highlighted the subsequent seven client service factors: "health promotion treatments," "mental learning," "experience of distinctive touristry resources," "complementary therapies," "relaxation," "healthy diet," and "social activities." in step with these service factors, the older adults interviewed were divided into a holistic cluster, physiocare cluster, and leisure and recreation cluster pattern cluster analysis. Finally, they planned socio-demographic variables for describing the actual characteristics of the three clusters better-known. Chen, K. H., Chang, F. H., \& Wu, C. (2013) have used the verbal-linguistic analysis to assess client service factors and every service item related to these factors and located eight crucial client service factors, from high to low, area unit personnel services, environments, healthy diet, relaxation, health promotion treatments, expertise of distinctive touristry resources, social activities, and mental learning. Medina-Munoz, D. R., \& Medina-Munoz, R. D. (2014) have analyzed an importance-performance-satisfaction and explained the attractiveness of destinations, attributes which will additionally vary in step with the traveller product approach was adopted, to spot the attributes that were vital for tourists travel to get pleasure from wellness vacations. Hjalager, A. M., \& Konu, H. (2011) mentioned Factors that facilitate or impede cooperative processes and models for co-creation and co-branding within the price chain and therefore the proof urged that the opportunities don't seem to be absolutely exploited for developments that enhance targeted place stigmatization. Rodrigues, Á., Kastenholz, E., \& Rodrigues, A. (2010) have mentioned potential implications on designing and management of rural touristry destinations, with stressed on the creation of integrated wellness product. The review of all the literature has shown the importance of things influencing the purchasers to shop for the wellness services and product. Most of the analysis results unconcealed the vacationers travel behaviour characteristics of the wellness touristry services generally.

\section{RESEARCH GAP}

Since prior studies have presented very few empirical research investigative wellness experiences as reported by tourists in the post experience period, it emerges and appropriate to bridge the research gap by inquiring the suggestions of unstructured content reviews. This could really much develop the understanding of wellness practices' key drivers and priorities. On account of address finally the research gap, objectives were defined that were the focus of studies presented in this paper.

\section{RESEARCH OBJECTIVE}

This study explores the potentially excellent prediction for the construction of a remarkable portfolio of study examined the variations among 3 groups of International tourist's: Beauty spa wellness customers, Health resort wellness customers, spiritual retreat wellness consumers socio demographic and travel behaviour characteristics in selecting wellness services at tourism destination.

\section{METHODOLOGY}

A research focused on tourists travel behavior 
characteristics and socio demographic factors were conducted among three different groups. This paper explored the target audience (international tourists) incorporated those travelers who go five tourism places in India: Chennai, Bangalore, Kottakal, \& Auroville. Survey was carried out in Chennai, Bangalore, Kottakal, \& Auroville during a self-managed survey. Respondents (global trotter) were approached by trained researchers and asked to participate in the survey. Researchers explained the rationale of the investigation, said that the study was nameless and handed a survey in suitable verbal communication. Convenient sample was used for this survey. Places were preselected based on location and capacity. The questionnaire was constructed for the intention of gathering data. It consisted of questions which were divided in to three sections. The first section of questions was designed to gather respondents' socio demographic characteristics (age, educational qualification, marital status, number of dependents, country of origin, house hold income, employment status, reason for coming to India, and sources of information) The second section of questions involved travel behaviour characteristics (holiday package, with personal friends, with partner/ spouse, with family members other than spouse, by yourself. Three types of consumers namely Beauty spa wellbeing consumers, Health resort wellbeing consumers and Spiritual retreat wellbeing visitors. With admiration to choosing touristry industry and their socio demographic, travel distinctiveness. Dissimilarity amongst wellness groups and variables connected to choosing touristry destination and travel distinctiveness of responders were resolute by chi square analysis.

\section{RESULTS AND DISCUSSION}

Testing of Hypothesis: Wellness Tourist Groups' Characteristics

$\mathrm{H}_{1}$ - The three groups of wellness tourists differ according to demographic and travel behaviour characteristics.

Few chi square tests for independence were performed to check if there exist any significant differences among the three groups of wellness tourists (Beauty Spa, spiritual retreat and lifestyle resorts visitors) with respect to their demographic and travel behaviour characteristics. Table-1 illustrates the descriptive statistic of the relative frequencies across the three groups of wellness tourists, as well as the sum percentage and number of respondents. The results of the chi-square tests comparing the demographic variables and the three groups of wellness tourists are also shown in the table 1.

\section{Table 1. Demographic profile of the three groups of Wellness tourists}

As in this sample survey more than $50 \%$ of the wellness tourists were male closely followed by female. To check if this was typical of the total population, a chi-square test for Independence was performed. The chi-square value obtained was not significant $(p=0.336>0.05)$ so the sampling distribution cannot be considered as representing the population parameter, i.e. both men and women were equal in proportion while visiting other countries for wellness tourism.
Similarly, there was no specific preference for Beauty spa or lifestyle resort or spiritual retreat among both men and women because of the non significant difference in chi-square test Wellness tourists are generally attracted towards the wellness centers based on the location of the center (Hill side, Sea side or Inland Waterways),

\begin{tabular}{|c|c|c|c|c|c|c|c|}
\hline \multirow{3}{*}{ Demogr aphy } & \multicolumn{3}{|c|}{ Wellness Tourist Type } & & & \multicolumn{2}{|c|}{ Chi-Square } \\
\hline & \multirow{2}{*}{\begin{tabular}{|l|} 
Beauty \\
Spa
\end{tabular}} & \multirow{2}{*}{\begin{tabular}{|l|} 
Lifestyle \\
Resort \\
$0 \%$ \\
\end{tabular}} & $\begin{array}{l}\text { Spiritual } \\
\text { Retreat }\end{array}$ & & & & \\
\hline & & & $\%$ & $\bar{N}$ & Total $\%$ & ? & $?$ \\
\hline Gender & & & & 420 & & 2.184 & 0.336 \\
\hline Female & $44.3 \%$ & $40.6 \%$ & $35.5 \%$ & 172 & $49 \%$ & & \\
\hline Male & $55.7 \%$ & $59.4 \%$ & $64.5 \%$ & 248 & $51 \%$ & & \\
\hline Age & & & & 4420 & & 18.872 & 0.092 \\
\hline $18-24$ & $21.6 \%$ & $15.6 \%$ & $19.6 \%$ & 81 & $19.3 \%$ & & \\
\hline $25-34$ & $23.8 \%$ & $20.3 \%$ & $20.6 \%$ & 92 & $21.9 \%$ & & \\
\hline $35-44$ & $33.0 \%$ & $33.6 \%$ & $37.4 \%$ & 144 & $34.3 \%$ & & \\
\hline $45-54$ & $11.9 \%$ & $18.8 \%$ & $13.1 \%$ & 60 & $14.3 \%$ & & \\
\hline $55-64$ & $7.0 \%$ & $9.4 \%$ & $9.3 \%$ & 35 & $8.3 \%$ & & \\
\hline $65-74$ & $2.79 \%$ & $0.0 \%$ & $0.0 \%$ & 5 & $1.2 \%$ & & \\
\hline 75 and more & $0.0 \%$ & $2.3 \%$ & $0.0 \%$ & 3 & $0.7 \%$ & & \\
\hline Education & & & & 420 & & 22.467 & 0.070 \\
\hline Primary School & $14.6 \%$ & $20.3 \%$ & $5.6 \%$ & 59 & $14.0 \%$ & & \\
\hline Sec ondary School & $25.9 \%$ & $24.2 \%$ & $29.0 \%$ & 110 & $26.2 \%$ & & \\
\hline Apprenticeship & $20.5 \%$ & $20.3 \%$ & $29.0 \%$ & 95 & $22.6 \%$ & & \\
\hline College TAFE & $16.8 \%$ & $8.6 \%$ & $12.1 \%$ & 55 & $13.1 \%$ & & \\
\hline Diploma & $4.3 \%$ & $8.6 \%$ & $8.4 \%$ & 28 & $6.7 \%$ & & \\
\hline Undergraduate & $5.4 \%$ & $7.0 \%$ & $2.8 \%$ & 22 & $5.2 \%$ & & \\
\hline University degree & $5.4 \%$ & $7.0 \%$ & $6.5 \%$ & 26 & $6.2 \%$ & & \\
\hline P.G. degree & $7.0 \%$ & $3.9 \%$ & $6.5 \%$ & 25 & $6.0 \%$ & & \\
\hline Emplos ment & & & & 420 & & 10.117 & 0.257 \\
\hline Full-time Student & $9.2 \%$ & $13.3 \%$ & $18.7 \%$ & 54 & $12.9 \%$ & & \\
\hline Futl-time Employed & $42.2 \%$ & $40.6 \%$ & $35.5 \%$ & 168 & $40.0 \%$ & & \\
\hline Part-time Employed & $36.8 \%$ & $29.7 \%$ & $32.7 \%$ & 141 & $33.6 \%$ & & \\
\hline Retired Home Duties & $5.9 \%$ & $4.7 \%$ & $5.6 \%$ & 23 & $5.5 \%$ & & \\
\hline No Employed & $5.9 \%$ & $11.7 \%$ & $7.5 \%$ & 34 & $8.1 \%$ & & \\
\hline Family Income & & & & 420 & & 31309 & 0.005 \\
\hline Less than 19,999 & $9.2 \%$ & $2.3 \%$ & $2.8 \%$ & 23 & $5.5 \%$ & & \\
\hline 20,000 to 49,999 & $28.6 \%$ & $22.7 \%$ & $29.9 \%$ & 114 & $27.1 \%$ & & \\
\hline 50,000 to 79,999 & $34.1 \%$ & $30.5 \%$ & $25.2 \%$ & 129 & $30.7 \%$ & & \\
\hline 80,000 to 109,999 & $18.9 \%$ & $28.9 \%$ & $23.4 \%$ & 97 & $23.1 \%$ & & \\
\hline 110,000 to 139,999 & $3.8 \%$ & $10.2 \%$ & $6.5 \%$ & 27 & $6.4 \%$ & & \\
\hline 140,000 to 169,999 & 2.79 & $3.1 \%$ & $8.4 \%$ & 18 & $4.3 \%$ & & \\
\hline 170,000 to 199,999 & $0.0 \%$ & $0.0 \%$ & $1.9 \%$ & 2 & $.5 \%$ & & \\
\hline $230,000+$ & $2.7 \%$ & $2.3 \%$ & $1.9 \%$ & 10 & $2.4 \%$ & & \\
\hline Country of Origin & & & & 420 & & 34.868 & 0.070 \\
\hline US & $14.6 \%$ & $7.8 \%$ & $7.5 \%$ & 45 & $10.7 \%$ & & \\
\hline Canada & $15.7 \%$ & $10.2 \%$ & $11.2 \%$ & 54 & $12.9 \%$ & & \\
\hline Mexico & $11.9 \%$ & $14.8 \%$ & $18.7 \%$ & 61 & $14.5 \%$ & & \\
\hline Poland & $11.4 \%$ & $7.8 \%$ & $6.5 \%$ & 38 & $9.0 \%$ & & \\
\hline Australia & $3.2 \%$ & $10.2 \%$ & $4.7 \%$ & 24 & $5.7 \%$ & & \\
\hline Swaden & $3.2 \%$ & $5.5 \%$ & $4.7 \%$ & 18 & $4.3 \%$ & & \\
\hline Russia & $15.1 \%$ & $12.5 \%$ & $13.1 \%$ & 58 & $13.8 \%$ & & \\
\hline Europe & $15.7 \%$ & $21.1 \%$ & $20.6 \%$ & 78 & $18.6 \%$ & & \\
\hline British & $0 \%$ & $2.3 \%$ & $0.0 \%$ & 3 & $0.7 \%$ & & \\
\hline South Africa & $3.2 \%$ & $.8 \%$ & $3.7 \%$ & 11 & $2.6 \%$ & & \\
\hline Korea & $3.2 \%$ & $3.9 \%$ & $4.7 \%$ & 16 & $3.8 \%$ & & \\
\hline Thailand & $2.2 \%$ & $1.6 \%$ & $.9 \%$ & 7 & $1.7 \%$ & & \\
\hline France & $.5 \%$ & $1.6 \%$ & $\longdiv { 3 . 7 \% }$ & 7 & $1.7 \%$ & & \\
\hline
\end{tabular}

type of rejuvenation method (Ayurvedic, Reiki, Yoga, Unani, Naturopathy, Siddha and Allopathic), and the cost of their stay. Hence it was not clear whether the wellness travelers have high preference to any of the three wellness types.

While inspecting the distribution of age among the three types of wellness travelers it was moderately significant to note the differences existing between them. The preference for beauty spa visitation was more among the 18-24(21.6\%) $\& 25-34(23.8 \%)$ age categories than the other age groups. This was followed by the number of people visiting spiritual retreats among age groups $18-24(19.6 \%), 25-34(20.6 \%)$ \& $35-44(37.4 \%)$ while it was not so in the other categories.

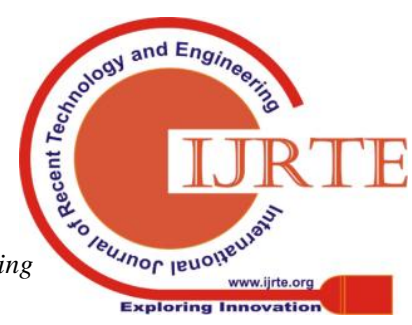


Preference for lifestyle resorts was more prominent in the age group $45-54(18.8 \%) \& 55-64(9.4 \%)$ than other types of wellness travel purposes. It may be because of the need for wellness while a person is still in his middle ages. The preference for beauty spa among youngsters is justifiable because personal care is a booming market more patronized by the younger generation.

The distribution of wellness travelers based on their educational attainment was not uniform across the sample of wellness travelers. Preference for beauty spa was well pronounced among travelers qualified in primary education and junior college grade but equal preference for all the three types was apparent among those qualified in secondary school. Travelers from vocational stream showed more preference towards spiritual retreats whilst those who had collegiate education showed equal preferences to all three types. The chi-square test for association among the level of education and the type of wellness travel though was moderately significant could not deduce any major conclusion to establish a connection between education and preference for specific travel type.

There was no significant association between the employment status and preference for specific type of wellness travel among the sample studied as per the chi-square test for association as shown in the table above. From the status of employment it is clear that visitation to beauty spa is more pronounced among those employed than to other centers. While students show preference to spiritual retreats more than other two types, lifestyle resorts were the choice of destination for those unemployed. Retirees show mixed preferences to visit all the three types. A larger sample could illustrate a clearer pattern of preferences between types of wellness tourist destination.

There was a significant association between the family income and the preference for type of wellness travel destination. Preference for beauty spa visitation was more among those with less than 19,999 USD a year. Those with income between 20,000 and 49,999 USD showed mixed interest to visit both beauty spa and spiritual retreat, whereas among those who drew between 50,000 and 79,999 USD income preference for beauty spa visitation is more pronounced than spiritual retreat. As the income drawn increases preference for beauty spa visitations reduces and visitation to spiritual retreat increases as per this sample. The association between high income and need for spiritual retreat visitation showed the increase in stress levels pushing one to take a spiritual sojourn as they go up their career ladder. Among the middle income group visitation to lifestyle resorts happened to be the second most important choice for rejuvenation.

Majority of the wellness tourists (95\% of 420) hail from non Asian countries especially Russia, US, Canada, Mexico and Europe only. Predominantly the tourists thronged to both beauty spa and spiritual retreat centers. India is known for several water bodies across the country where beauty spa treatments aligned with Indian medicinal therapies are offered by such centers. Especially mud therapy, ayurvedic cure with medicinal plant extracts, oil massage and the like are practiced here attracting tourists to repeatedly return to such centers year on year. India is a land of diverse cultural dispersion with spiritual healing practiced in almost all religions. Wellness tourists seek spiritual cleansing by visiting such centers for psychological wellbeing. Wellness tourism centers are strategically located near seafaring sites, river fronts, and deep forests, near hillocks and amidst mountainous locations, so to improve the living experience of the visitors. Though the sample distribution is dispersed well it is not significant enough to conclusively prove it as a population characteristic and hence should be accepted with caution.

Travel Behaviour Characteristics of wellness travelers were assessed as shown in table 2. Travel behaviour measures included information about with whom wellness travelers travelled for wellness vacations, number of years of wellness tourism experience, number of times visited a particular wellness centre and the various wellness tourism destination they visited in India.

Table 2. Travel Behaviour Characteristics of Wellness Tourists

\begin{tabular}{|c|c|c|c|c|c|c|c|}
\hline \multirow{3}{*}{$\begin{array}{ll}\text { Travel } & \text { Behatiour } \\
\text { Characteristics } & \end{array}$} & \multicolumn{3}{|c|}{ Wellhess Tourist Type } & & & \multirow{2}{*}{\multicolumn{2}{|c|}{ Chi-Square }} \\
\hline & $\begin{array}{l}\text { Beauty } \\
\text { Spa } \\
\end{array}$ & \begin{tabular}{|l|} 
Lifestyle \\
Resort \\
\end{tabular} & \begin{tabular}{|l|} 
Spiritual \\
Retreat \\
\end{tabular} & & & & \\
\hline & 96 & $9 \%$ & 96 & $\mathrm{~N}$ & Total \% & ? & $?$ \\
\hline Visit As a Part of Travel Package & 77.83 & 85.16 & 93.45 & $353 / 420$ & 78.40 & 13.10 & 0.108 \\
\hline Visit with personal friend & 93.51 & 87.50 & 88.78 & $380 / 420$ & 90.47 & 13.80 & 0.087 \\
\hline $\begin{array}{l}\text { Visit with partner/Spovse } \\
\text { Visit with oher family members } \\
\text { Visit alone }\end{array}$ & $\begin{array}{l}85.40 \\
87.02 \\
75.67\end{array}$ & $\begin{array}{l}87.50 \\
91.41 \\
85.16\end{array}$ & $\begin{array}{l}82.24 \\
91.59 \\
83.18 \\
\end{array}$ & $\begin{array}{l}358 / 420 \\
376 / 420 \\
338 / 420\end{array}$ & \begin{tabular}{|l|}
85.24 \\
89.50 \\
80.48
\end{tabular} & $\begin{array}{l}23.457 \\
19.20 \\
15.91 \\
\end{array}$ & \begin{tabular}{|l|}
0.003 \\
0.014 \\
0.04 \\
\end{tabular} \\
\hline $\begin{array}{l}\text { No of Year s in wellne is Travel } \\
\text { Lass than two years visited }\end{array}$ & 41.10 & 35.20 & 37.40 & \begin{tabular}{|l|}
418 \\
161 \\
\end{tabular} & 38.30 & 12.41 & 0.134 \\
\hline Berween 3 and 4 Years visited & 46.50 & 43.80 & 7.50 & 188 & 44.80 & & \\
\hline Bertween 5 and 6 Years visited & 8.10 & 14.10 & 12.10 & 41 & 9.80 & & \\
\hline Above 6 years visited & 3.80 & 6.30 & 12.10 & 28 & 6.70 & & \\
\hline $\begin{array}{l}\text { No. of Visits in the past } 12 \\
\text { months }\end{array}$ & & & & 418 & & 12.41 & 0.134 \\
\hline $\begin{array}{l}\text { Less than } 2 \text { Visits } \\
\text { Bermeen } 3 \& 4 \text { Visits }\end{array}$ & 27.0 & 43.0 & 27.10 & \begin{tabular}{|l|}
134 \\
196
\end{tabular} & $\begin{array}{l}31.90 \\
46.70\end{array}$ & & \\
\hline $\begin{array}{l}\text { Between } 3 \& 4 \text { Visits } \\
\text { Between } 5 \text { \& } 6 \text { Visits }\end{array}$ & $\begin{array}{l}51.40 \\
15.10 \\
\end{array}$ & \begin{tabular}{|l|}
38.30 \\
14.10 \\
\end{tabular} & $\begin{array}{l}48.00 \\
15.00 \\
\end{array}$ & \begin{tabular}{|l|}
62 \\
62
\end{tabular} & \begin{tabular}{|l|}
70.10 \\
14.80 \\
\end{tabular} & & \\
\hline More than 6 Visits & 3.80 & 6.30 & 12.10 & 28 & 6.70 & & \\
\hline Other States risited & & & & 420 & & & \\
\hline Tamilnadu & 76.20 & 79.68 & 99.85 & 333 & 79.28 & 9.739 & 0.284 \\
\hline Kamataka & 79.46 & 88.28 & 80.37 & 346 & 82.38 & 19.252 & 0.014 \\
\hline Kerala & 88.65 & 85.94 & 89.71 & 370 & 88.09 & 4.593 & 0.800 \\
\hline Andrapradesh & 81.62 & 83.59 & 85.98 & 348 & 82.85 & 14,450 & 0.071 \\
\hline Bangalore & 89.19 & 87.50 & 86.91 & 370 & 88.09 & 3.100 & 0.98 \\
\hline Goa & 91.35 & 83.59 & 86.91 & 369 & 87.85 & 7.030 & 0.533 \\
\hline Pondicherry & 80.00 & 83.59 & 79.44 & 340 & 80.95 & 11.54 & 0.317 \\
\hline Himalayas & 85.97 & 89.84 & 82.24 & 362 & 86.19 & 12.827 & 0.118 \\
\hline Mumbai & 86.48 & 89.06 & 85.98 & 366 & 87.14 & \begin{tabular}{|l|}
11.831 \\
\end{tabular} & 0.159 \\
\hline Bihar & 87.02 & 90.63 & 99.85 & 367 & 87.38 & 8.966 & 0.345 \\
\hline Others & 87.56 & 85.93 & 82.24 & 360 & 85.71 & 5.923 & 0.656 \\
\hline
\end{tabular}

As in the table 2 there is no significant difference existed among different types of wellness travelers with respect to their preference to travel with friends, spouse, relatives or travel alone though spiritual retreat travel along with family members, travel alone and as a part of travel package showed a significant increase than other two types of travelers indicating a preference for packaged travel with or without family members to spiritual retreat centers. Visits to beauty spa centers along with personal friend showed the power of positive word of mouth communication because friends encouraged the travelers to try and engage in beauty related wellness services. Visits to lifestyle resorts showed a preference to travel with or without spouse among the travelers depicting a need for personal wellbeing away from home and office.

The number of years one has visited a wellness 
tourist centre would show the repeat behaviour of a wellness traveler to prefer a wellness centre over other centers. In the present study it was questioned that how many years since the traveler had visited India for the purpose of wellness. It ranged from less than a year to more than six years. Among the category of visitors, it was found that spiritual retreat visitors showed the maximum years of experience with 1.94 mean value( $\mathrm{SD}=0.969)$, closely followed by lifestyle resort visitors at mean of $1.93(\mathrm{SD}=0.88)$, and $\mathrm{Spa}$ retreat visitors at mean of $1.76(\mathrm{SD}=0.78)$. There exists a significant association between travel experience and the preference for the type of wellness travel category. With the rich culture and heritage India definitely boasts that the wellness travelers had thronged Indian spiritual retreat centers over a long period as is evident in the mean score above, wherein lifestyle resort visits fell closely at second place in terms of preference and beauty spa visitations had a late origin after the advent of medical technologies and proliferation of commercial centers focusing on aspiring visitors for beauty augmentations.

To know how many times one had paid a visit to a wellness center, a specific question on how many number of times visited was asked. The responses were grouped in to less than 2 visits, between 2 and 4 visits, between 4 and 6 six visits and more than 6 visits. It is quite likely that someone would have paid a visit to a spa more times than to a wellness resort because of the short stay it required at these centers. Both spiritual and Beauty spa visitors had more visits within a year's span, with spiritual retreat at a mean visitation of 2.09 ( $\mathrm{SD}=0.966)$ and Beauty SPA visits at a mean visitation of $2.03(\mathrm{SD}=0.89)$. Lifestyle resorts stood at an average visit of 1.81 times $(\mathrm{SD}=0.87)$ when compared with the rest. The association between the category of wellness travel visits and the frequency of visits shows a significant relationship as is evident in the present study. Preference for Beauty spa visitation and spiritual retreat visitation was more than two occasions in a year than visit to a wellness lifestyle resort which is less than 2 visits per year. This clearly shows the dominance of India in bringing wellness travelers who are inclined more to spiritual healing powers than those who prefer a wellness solution alone. Also beauty spa visits show high frequency visits because of most economical cosmetic therapies offered in here compared to other developed economies.

On the preference for a specific state in India for wellness travel, there was no significant difference among the wellness tourists for SPA, lifestyle or spiritual resort choices although each state in India has its unique attractions for general tourists. Tamilnadu known for its spiritual and cultural richness also hosts several wellness centers at several places where international tourists frequent for services. Kerala houses one of the ancient treatment forms of India namely Ayurveda. Many centers in Kerala are abodes of ayurvedic cures and rehabilitation therapies for ailments for which other forms of medicine do not yield desired results. Karnataka and Andrapradesh are cultural hotpots where wellness travel is not well pronounced. Goa \& Pondicherry have many SPA based centers where many international tourists flock round the year. Himalayas is known for natural springs and serene locations to please the visiting tourists and so houses so many spiritual and wellness centers. Mumbai is the fashion capital of India where many cosmetic therapy centers have mushroomed during the last two decades. Hence it is clear that each and every place in India has a reason to attract the wellness tourists and hence offer services for the needy.

\section{CONCLUSION}

To conclude, the above inferences of the three categories of wellness tourists showed significant differences among them based on their demographic and travel behaviour characteristics. Wellness tourists have differing needs of wellness which are evident from their differing demographic and travel patterns as they visit India for fulfilling those needs. Thus, hypothesis was confirmed about their heterogeneity. Though there is a belief of wellness touristry in India, wellness touristry as a part of touristry propose been started in the most recent decade in nearly all wellness service centers since earlier the tone of voice exist on remedial facets of wellness touristry. Taking into consideration than the best part of touristry resides in India exist associated to beauty spa, health resorts, in addition to spiritual retreat fondness's and the majority of them are income created, and wellness touristry turn into a market sector which coats this two parts. Wellbeing is generally associated to harmony, peacefulness and secluded location so the consumer of wellbeing habitually goes ahead a special way of life Aviles by the users. Wellness touristry has come out as a touristry with scrupulous fondness and socio demographic distinctiveness. Established on this hypothesis our respondents were alienated into three sets of wellness tourists according to their first choice towards wellbeing and disparities amongst the types with value to choosing touristry destination and travel behaviour characteristics were investigated. There are a few confines of this work. Since these outcome are support on suitable sample of visitors that stayed Kerala, Karnataka, Tamilnadu and Pondicherry in India. Respondents are international tourists and stayed at least one night in most preferred one among the three types of wellness service centers. The consequences might not be widespread to the on the whole Indian wellness industry. Facts were composed on site where the respondents were international tourists to India and the outcome might not accurately imitate their genuine inclinations for enchanting a wellbeing leisure travel.

\section{REFERENCES}

1. Mueller, H., \& Kaufmann, E. L. (2001). Wellness tourism: Market analysis of a special health tourism segment and implications for the hotel industry. Journal of vacation marketing, 7(1), 5-17.

2. Kickbusch, I., \& Payne, L. (2003). Twenty-first century health promotion: the public health revolution meets the wellness revolution.

3. Smith, M., \& Kelly, C. (2006). Holistic tourism: Journeys of the self?. Tourism Recreation Research, 31(1), 15-24.

4. Smith, M., \& Puczkó, L. (2008). Health and wellness tourism. Routledge.

5. Laing, J., \& Weiler, B. (2008). Mind, body and spirit: Health and wellness tourism in Asia. Asian tourism: Growth and change, 379-389

6. Erfurt-Cooper, P., \& Cooper, M. (2009). Health and wellness tourism: Spas and hot springs. Channel view publications.

7. ZHOU, B., \& FANG, W. (2012). Comments on Domestic Wellness Tourism Research [J]. In Tourism Forum (Vol. 1, p. 009).

8. Kelly, C. (2010). Analysing wellness tourism provision: A retreat operators' study. Journal of Hospitality and Tourism Management, 17(1), 108-116. 
9. Voigt, C., Brown, G., \& Howat, G. (2011). Wellness tourists: in search of transformation. Tourism Review, 66(1/2), 16-30.

10. Lehto, X. Y., Brown, S., Chen, Y., \& Morrison, A. M. (2006). Yoga tourism as a niche within the wellness tourism market. Tourism Recreation Research, 31(1), 25-35.

11. Heung, V. C., \& Kucukusta, D. (2013). Wellness tourism in China: Resources, development and marketing. International journal of tourism research, 15(4), 346-359.

12. Chen, K. H., Liu, H. H., \& Chang, F. H. (2013). Essential customer service factors and the segmentation of older visitors within wellness tourism based on hot springs hotels. International Journal of Hospitality Management, 35, 122-132.

13. Chen, K. H., Chang, F. H., \& Wu, C. (2013). Investigating the wellness tourism factors in hot spring hotel customer service. International Journal of Contemporary Hospitality Management, 25(7), 1092-1114.

14. Medina-Muñoz, D. R., \& Medina-Muñoz, R. D. (2014). The attractiveness of wellness destinations: An importance-performance-satisfaction approach. International Journal of Tourism Research, 16(6), 521-533.

15. Hjalager, A. M., \& Konu, H. (2011). Co-branding and co-creation in wellness tourism: The role of cosmeceuticals. Journal of Hospitality Marketing \& Management, 20(8), 879-901.

16. Rodrigues, Á., Kastenholz, E., \& Rodrigues, A. (2010). Hiking as a relevant wellness activity-results of an exploratory study of hiking tourists in Portugal applied to a rural tourism project. Journal of Vacation Marketing, 16(4), 331-343. 